Erratum

\title{
Erratum: Dieu, T.B. et al. A Novel Integrated Approach of Relevance Vector Machine Optimized by Imperialist Competitive Algorithm for Spatial Modeling of Shallow Landslides. Remote Sens. 2018, 10, 1538
}

Dieu Tien Bui ${ }^{1,2}$, Himan Shahabi ${ }^{3, *} \mathbb{C}$, Ataollah Shirzadi ${ }^{4}$ (D), Kamran Kamran Chapi ${ }^{4}$ (D), Nhat-Duc Hoang ${ }^{5}$, Binh Thai Pham ${ }^{6}\left(\mathbb{D}\right.$, Quang-Thanh Bui ${ }^{7}$, Chuyen-Trung Tran ${ }^{8}$,

Mahdi Panahi ${ }^{9}$ (D) Baharin Bin Ahmad ${ }^{10}$ and Lee Saro ${ }^{11,12, *}$ (1)

1 Geographic Information Science Research Group, Ton Duc Thang University, Ho Chi Minh City, Vietnam; dieu.t.bui@usn.no

2 Faculty of Environment and Labour Safety, Ton Duc Thang University, Ho Chi Minh City, Vietnam

3 Department of Geomorphology, Faculty of Natural Resources, University of Kurdistan, Sanandaj 66177-15175, Iran

4 Department of Rangeland and Watershed Management, Faculty of Natural Resources, University of Kurdistan, Sanandaj 66177-15175, Iran; a.shirzadi@uok.ac.ir (A.S.); k.chapi@uok.ac.ir (K.K.C.)

5 Faculty of Civil Engineering, Institute of Research and Development, Duy Tan University, P809-K7/25 Quang Trung, Danang 550000, VietNam; hoangnhatduc@dtu.edu.vn

6 Geotechnical Engineering and Artificial Intelligence Research Group (GEOAI), University of Transport Technology, Hanoi 100803, VietNam; binhpt@utt.edu.vn

7 Faculty of Geography, VNU University of Science, 334 Nguyen Trai, ThanhXuan, Hanoi 100803, VietNam; qthanh.bui@gmail.com

8 Faculty of Information Technology, Hanoi University of Mining and Geology, Pho Vien, Bac Tu Liem, Hanoi 100803, VietNam; trang.ch@gmail.com

9 Young Researchers and Elites Club, North Tehran Branch, Islamic Azad University, P.O. Box 19585/466 Tehran, Iran; panahi2012@yahoo.com

10 Department of Geoinformation, Faculty of Geoinformation and Real Estate, Universiti Teknologi Malaysia (UTM), 81310 Johor Bahru, Malaysia; baharinahmad@utm.my

11 Geological Research Division, Korea Institute of Geoscience and Mineral Resources (KIGAM), 124, Gwahak-ro Yuseong-gu, Daejeon 34132, Korea

12 Department of Geophysical Exploration, Korea University of Science and Technology, 217, Gajeong-ro Yuseong-gu, Daejeon 34113, Korea

* Correspondence: h.shahabi@uok.ac.ir (H.S.); leesaro@kigam.re.kr (L.S.); Tel.: +98-87-33-664-600 (H.S.); $+82-42-8683057$ (L.S.)

Received: 26 December 2018; Accepted: 27 December 2018; Published: 29 December 2018

check for updates

The authors wish to make the following corrections to this paper [1]: Please just change spell name of Baharin Bin Ahamd to Baharin Bin Ahmad

The authors would like to apologize for any inconvenience caused to the readers by these changes. 


\section{Reference}

1. Dieu, T.B.; Himan, S.; Ataollah, S.; Kamran, C.; Nhat-Duc, H.; Binh, T.P.; Quang-Thanh, B.; Chuyen-Trung, T.; Mahdi, P.; Baharin, B.A.; et al. A Novel Integrated Approach of Relevance Vector Machine Optimized by Imperialist Competitive Algorithm for Spatial Modeling of Shallow Landslides. Remote Sens. 2018, 10, 10-3390. [CrossRef] 